DOI: 10.12731/2070-7568-2018-4-7-26

УДК 677: 628.517.2

\title{
СИСТЕМА СБОРА ЭКОЛОГИЧЕСКОЙ ИНФОРМАЦИИ О СОСТОЯНИИ ТЕРРИТОРИАЛЬНОЙ ТЕХНОСФЕРЫ
}

\author{
Виноградов О.С., Виноградова Н.А., \\ Безбородова О.Е., Шерстнев В.В.
}

Эколого-экономическое состояние городов и сельскохозяйственных угодий является определяюшим для дальнейшего развития территорий. Глобальные экологические проблемы, связанные с возрастанием экономического ущерба от катастроф природного и техногенного характера, загрязнением воздушной и водной среды, почв, затрагивают интересы РФ и ее граждан. Экологическая ситуация в РФ характеризуется высоким уровнем техногенного воздействия на окружаюшую среду и человека, и связано это не только с последствиями промедшего экономического кризиса в нашей стране, но и с условиями хозяйствования, применяемыми в промышленности и сельском хозяйстве. Для эффективного функционирования системы комплексного мониторинга состояния территориальной техносферы чрезвычайно важным является научно обоснованное формирование сети постов мониторинга, то есть мест и способов размещения датчиков. Статья содержит общую схема сбора и передачи информации о результатах мониторинга, в соответствии с которой, подобраны и описаны группы стационарных и мобильных датчиков. Датчики служат для автоматического измерения и учета объема и массы выбросов, сбросов, коничентрации загрязняющих веществ в воздушной, водной средах и почве. Своевременное установление факта превышения предельно допустимых значений измеренных датчиками, сможет предотвратить развитие чрезвычайной ситуачии и сохранить жизнь и здоровье населения, а также снизить экономические затраты на последующую рекультивацию пораженных территорий. 
Цель: разработка общей схемы автоматического сбора и передачи экологической информации, в составе системы комплексного мониторинга территориальной техносферы, в режиме реального времени.

Метод или методология проведения работы: в статье использовались математические методы, а также аналитические методы анализа.

Результаты: впервые разработана и описана общая схема сбора и передачи информации о результатах комплексного мониторинга территориальной техносферы, с применение беспилотных летательных аппаратов, для автоматического измерения и учета состояния техносферы, позволяющая снизить экономический ущерб от загрязнения территорий и затрат на их последующую рекультивацию.

Область применения результатов: полученные результаты (схема мониторинга и приничипь ее построения) целесообразно применять для создания системы контроля воздействия на окружающую среду техногенных объектов. Причем в этих результатах могут быть заинтересованы как сами предприятия (для составления экологической отчетности, проведения экологического контроля и пр.), так и региональные экологические службы Российской Федерации.

Ключевые слова: экономика; техносферная безопасность; комплексный мониторинг; экологические службы; сбор информации; автоматические измерения.

\section{THE SYSTEM OF COLLECTING ENVIRONMENTAL INFORMATION ON THE STATE OF THE TERRITORIAL TECHNOSPHERE}

\section{Bezborodova O.E., Vinogradov O.S., Vinogradova N.A., Sherstnev V.V.}

The ecological and economic condition of cities and agricultural lands is decisive for the further development of territories. Global environmental 
problems associated with the increase in economic damage from natural and man-made disasters, pollution of the air and water environment, and soil affect the interests of the Russian Federation and its citizens. The ecological situation in the Russian Federation is characterized by a high level of anthropogenic impact on the environment and humans, and this is due not only to the consequences of the past economic crisis in our country, but also to the economic conditions applied in industry and agriculture. For the effective functioning of the system of integrated monitoring of the state of the territorial technosphere, it is extremely important to scientifically-based formation of a network of monitoring stations, that is, locations and methods of sensor placement. The article contains a general scheme for collecting and transmitting information on the results of monitoring, in accordance with which groups of fixed and mobile sensors are selected and described. Sensors are used to automatically measure and record the volume and mass of emissions, discharges, and concentrations of pollutants in air, water, and soil. Timely determination of the fact that the maximum permissible values measured by the sensors are exceeded will be able to prevent the development of an emergency situation and preserve the life and health of the population, as well as reduce the economic costs of the subsequent reclamation of the affected areas.

Purpose: development of a general scheme for the automatic collection and transmission of environmental information, as part of a comprehensive monitoring system of the territorial technosphere, in real time

Method or methodology of the work: the article used mathematical methods, as well as analytical methods of analysis.

Results: for the first time, a general scheme for collecting and transmitting information on the results of integrated monitoring of the territorial technosphere, using unmanned aerial vehicles, was developed and described for automatic measurement and recording of the state of the technosphere, which makes it possible to reduce the economic damage caused by the pollution of territories and the cost of their subsequent remediation.

The scope of the results: the results obtained (monitoring scheme and principles of its construction) should be used to create a system for monitoring the environmental impact of man-made objects. Moreover, both the 
enterprises themselves (for the preparation of environmental reporting, environmental monitoring, etc.) and the regional environmental services of the Russian Federation may be interested in these results.

Keywords: economics; technosphere safety; comprehensive monitoring; environmental services; collection of information; automatic measurements.

\section{Введение}

В настоящее время большой акцент делается на исследование эколого-экономического состояния окружающей среды. Вопросы эффективного управления воздействием человека на окружающую среду с целью оптимизации социально-экономических показателей развития региона, сохранения и развития сельских территорий являются актуальными и практически значимыми.

Теория экономического роста склонна отделываться от экологических последствий хозяйственного развития. Она исходит из предпосылки, что увеличение общественного продукта основывается только на таких факторах, как инвестиция капитала, применение рабочей силы и технический прогресс.

Созданные по всему миру системы контроля состояния окружающей среды призваны собирать и обрабатывать экологическую информацию в режиме реального времени для передачи лицу, принимающему решения или принимать решения самостоятельно на основании заложенных алгоритмов. Такие системы описаны в [1, $2,3]$. Эти системы отслеживают комплексы параметров, характеризующих состояние окружающей среды с учетом особенностей территориальной техносферы. Такие системы мониторинга состоят из совокупности датчиков, расположенных в местах проведения измерений, средств передачи измеренной информации в центральный пункт мониторинга и комплекса вычислительных средств, осуществляющих прием, накопление, хранение и обработку полученной информации. Вся собранная таким образом информация может быть использована для оценки состояния окружающей среды в режиме реального времени и регистрации фактов превышения предельно 
допустимых значений, а так же для моделирования и прогнозирования развития экологической ситуации в масштабах территориальной техносферы.

Экологизация экономики не является абсолютно новой проблемой. Практическое воплощение принципов экологичности тесно связано с познанием естественных процессов и достигнутым техническим уровнем производств. Новизна проявляется в эквивалентности обмена между природой и человеком на основе оптимальных организационно-технических решений.

Современные объекты техносферы являются сверхсложными системами, использующими различные технологии производства продукции, в том числе и средозащитные, позволяющие минимизировать ущерб окружающей среде еще на стадии производства, например, при нанесении гальванических покрытий. Причем на производственном уровне уже реализованы автоматизированные системы мониторинга, которые посредством датчиков контролируют и регулируют управляемую среду [4, с. 62]. Но исключить воздействия на окружающую среду только таким способом невозможно. Поэтому одной из задач государственной политики РФ в области экологического развития является совершенствование системы комплексного мониторинга и прогнозирования состояния территориальной техносферы [5].

\section{Основная часть}

Для успешного развития хозяйствующего субъекта необходимо обеспечить его экономические интересы. Устойчивое развитие дает возможность экономическим субъектам чувствовать уверенность в завтрашнем дне и строить планы на перспективу. Именно в этих условиях субъекты начинают задумываться об экологических аспектах своей деятельности с целью дальнейшего успешного функционирования.

Экономические интересы стимулируют производство [6, с. 120], необходимо создать такие условия, чтобы хозяйствующим субъектам было выгодно заниматься вопросами экологии. Развитие 
системы мониторинга территорий дает возможность хозяйствующим субъектам отследить наиболее уязвимые участки своего производства и принять соответствующие меры. Особенно, это актуально для сельскохозяйственных предприятий, т.к. постоянный мониторинг содержания химических компонентов в почвах дает возможность получать экологически чистый продукт. Здесь чрезвычайно важно правильно устанавливать датчики мониторинга. В основном, сельское хозяйство, рассматривается как одна из отраслей народного хозяйства региональной экономики. Следовательно, управление сельскими территориями на основе диверсификации экономики базируется на тех научных воззрениях, которые доминируют в настоящее время [7, с. 115]. Сейчас принцип экологизации сельскохозяйственного производства является весьма актуальным, однако перевести эту отрасль народного хозяйства на экологически грамотный путь развития не так то просто. Связано это в том числе и с необходимостью постоянного мониторинга за состоянием посевных площадей. Такой мониторинг должен быть дешев и доступен сельхозпроизводителям. Использование нашей модели, включая систему беспилотных летательных аппаратов, пока решает только вопрос мониторинга, но экономически выгодным он станет только тогда, когда будет внедрена федеральная или региональная программа мониторинга сельхозугодий.

Мониторинг качества сельхозугодий обеспечивает принцип рационального природопользования в сельском хозяйстве, который вытекает из принципов расширенного воспроизводства природных ресурсов, ограниченности природных ресурсов, экологической безопасности, взаимосвязи экономической и технологической составляющих производственного процесса, максимизации эколого-экономического эффекта [8, с. 198].

Для получения достоверной информации о распространении в окружающей среде выбросов и сбросов загрязняющих веществ (3В) необходимо правильно выбрать места для размещения датчиков. Сеть постов мониторинга располагается строго определенным образом, учитывающим представительность системы пробоотбора; 
розу ветров, порядок проведения и регулярность пробоотбора. Конечно, мониторинг агромелиоративных систем закладывает основу для формирования систем высококачественного агропроизводства, а это прямой путь повышения эффективности земельно-имущественных отношений в целом [9, с. 112].

Кроме мониторинга сельхозугодий не следует упускать из виду и мониторинг промышленных территорий, а также мониторинг городской среды в целом.

В предлагаемой системе комплексного мониторинга предлагается использовать три группы датчиков.

Первая группа стационарных датчиков автоматического измерения и учета объема и/или массы выбросов, сбросов, концентрации загрязнителей в воздушной, водной средах, почве размещается в непосредственной близости от источника воздействия. Их количество и месторасположения определяют по разрешительной документации предприятий, а именно проектами ПДВ, НДС.

Вторая группа стационарных датчиков измерения и учета концентрации ЗВ в воздушной, водной средах, почве размещается в наиболее проблемных зонах контролируемой территории.

Для обоснованного выбора мест размещения второй группы датчиков автоматического измерения и учета объема и/или массы выбросов, сбросов, концентрации загрязнителей в воздушной, водной средах, почве сначала необходимо составить базу данных. База данных включает в себя информацию по концентрациям загрязняющих веществ в различных средах исследуемого региона. Далее следует провести анализ полученной информации, определить и установить связь между источниками воздействия (предприятия) и загрязнителями, а также сформировать комбинации «источник - загрязняющее вещество». Для всех комбинаций «источник - загрязняющее вещество» надо определить зоны активного загрязнения. В местах наложения зон активного загрязнения от нескольких предприятий установить посты стационарных датчиков второй группы контроля ЗВ в воздушной, водной средах, почве (см. рис. 1). 


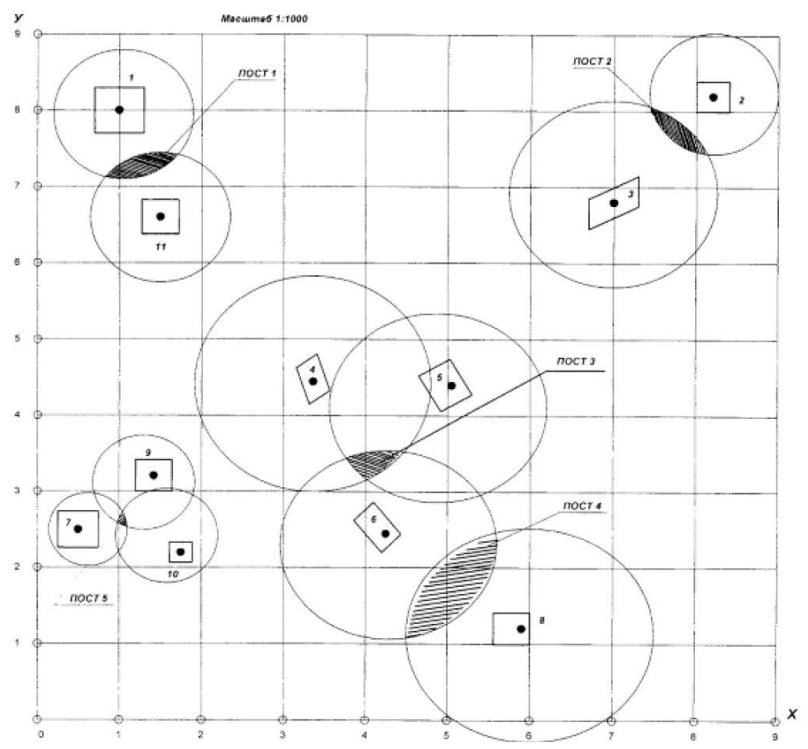

Рис. 1. Образование зон активного загрязнения и размещение постов контроля воздушной среды [10]

Все датчики второй группы оснащают техническими средствами передачи информации в центральный диспетчерский пункт и дальше в государственный фонд данных государственного экологического мониторинга. Такими техническими средствами передачи информации могут быть телефонные проводные каналы, радиосвязь, спутниковая связь.

Оптимальное количество постов наблюдения и сбора инфор-

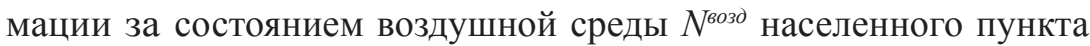
определяем по формуле [11]:

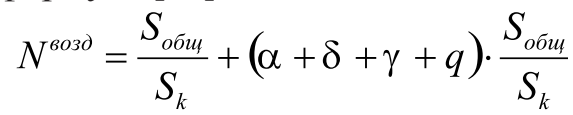

где $S_{\text {общ }}$ - общая площадь городской территории, км²;

$S_{k}$ - среднестатистическая площадь городской территории, обслуживаемая одним постом наблюдения, равная 15 км²

$\alpha$ - коэффициент, учитывающий рельеф местности и равный: 0,1 - для равнинной местности, 0,3 - для горной местности; 
$\sigma$ - коэффициент, учитывающий характер загрязнения;

$\gamma$ - коэффициент, учитывающий количество автотранспорта в городе и равный: 0 - для городов с количеством автотранспорта до 50 тыс., 0,1 - для городов с количеством автомобилей от 50 до 100 тыс., 0,2 - для городов с количеством автомобилей от 100 до 200 тыс., 0,3 - для городов с количеством автомобилей более 200 тыс.;

$q$ - коэффициент, учитывающий характер, распределение источников загрязнения на городской территории.

Оптимальное количество постов наблюдения и сбора информа-

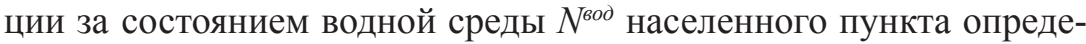
лялся по формуле:

$$
N^{\text {вод }}=\frac{L_{\text {оби }}}{L_{k}}+(\alpha+\delta+\gamma+q) \cdot \frac{L_{\text {оби }}}{L_{k}}
$$

где $L_{\text {общ }}$ - протяженность водного объекта в пределах городской территории, км;

$L_{k}-$ среднестатистическая протяженность участка реки, обслуживаемая одним постом наблюдения, равная 1,5 км;

$\alpha$ - коэффициент, учитывающий рельеф местности и равный: 0,1 - для равнинной местности, 0,3 - для горной местности;

$\sigma$ - коэффициент, учитывающий характер загрязнения;

$\gamma$ - коэффициент, учитывающий количество предприятий осуществляющих сброс сточных вод в водные объекты в городе и равный: 0,1 - для городов с количеством предприятий до 10 тыс., 0,2 для городов с количеством предприятий от 10 до 20 тыс., 0,3 - для городов с количеством предприятий от 20 до 30 тыс., 0,4 - для городов с количеством предприятий более 30 тыс.;

$q$ - коэффициент, учитывающий характер, распределение источников загрязнения на городской территории.

В соответствии с [12] государственный экологический мониторинг определяется как комплексные наблюдения за состоянием окружающей среды, естественных экологических систем, за происходящими в них процессами и явлениями, а так же оценка и прогноз изменений состояния окружающей среды. 
Посты наблюдения и сбора информации за состоянием почвы в населенном пункте совмещают с водными и воздушными постами [3, с. 157].

Для этих целей может быть использована автоматическая система непрерывного мониторинга промышленных выбросов 2, 3 (см. рис. 2). А также поточные и погружные анализаторы контроля качества воды 2, 3 .

Передача информации от датчиков второй группы может производиться любым доступным образом - по радиоканалу, проводным радиосетям, Wi-Fi и пр.

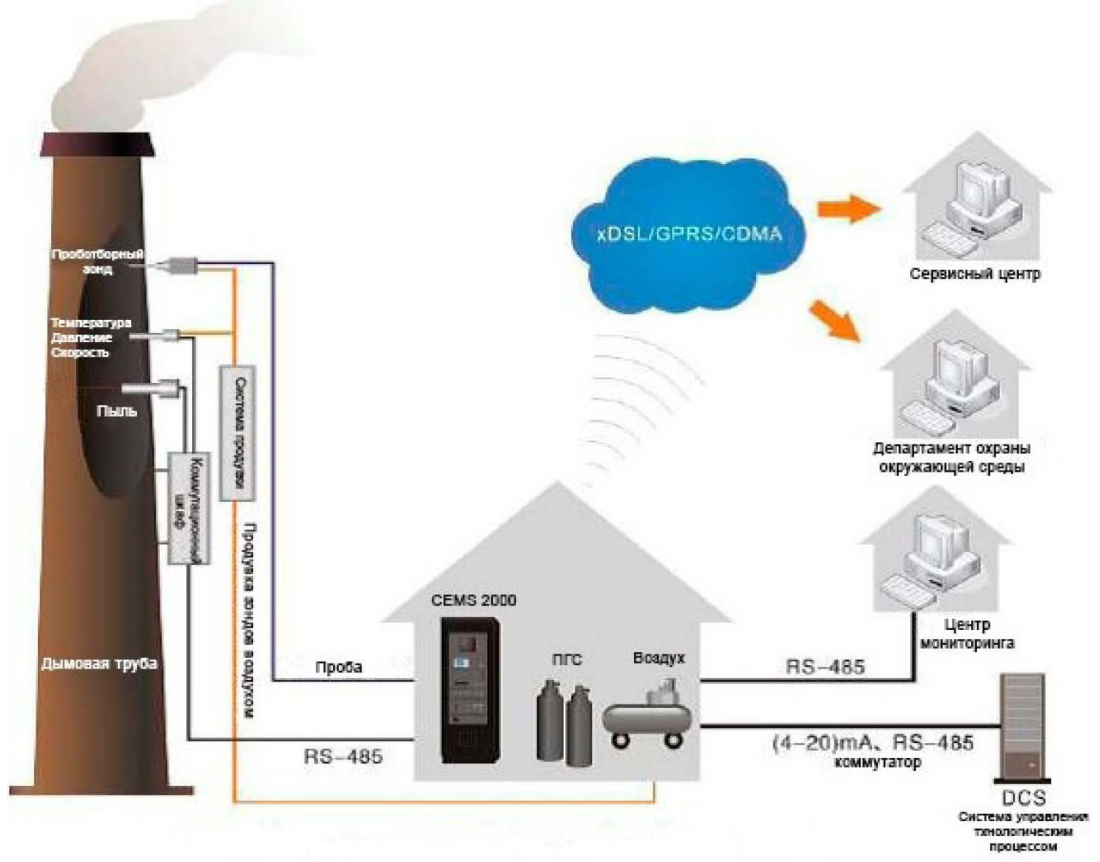

Рис. 2. Схема расположения датчиков первой группы для контроля воздушной среды

Датчики третьей группы дистанционного контроля состояния окружающей среды могут быть размещены на беспилотных летательных аппаратах (БЛА). БЛА вылетают в зону измерений по 
специальному заданию (в случае выхода из строя стационарного датчика, пока его не заменили или в случае чрезвычайной ситуации, когда персонал для уточнения обстановки отправлять опасно), информация с них передается на центральный диспетчерский пункт по различным системам связи (радиосвязь, спутниковая связь).

Кроме датчиков контроля состояния окружающей среды, БЛА могут быть оборудованы приборами для сбора информации о поражающих факторах в зоне чрезвычайной ситуации, минимизация уровня их воздействия, мониторинг участка зоны. Различными исследовательскими группами ведутся работы по использованию БЛА не только для выявления проблем, связанных с разрушением промышленных и транспортных объектов (например, трещины на асфальте, мостах и фасадах зданий), но и проведению ремонтных работ. Для технического обслуживания и ремонта инфраструктуры уже сейчас возможно использование технологии 3D-печати в сочетании с БЛА. Есть технические решения для размещения 3D-принтеров на БЛА, чтобы прямо на площадке изготавливать запасные части для поврежденных элементов инфраструктуры. В 2014 году был создан первый летающий 3D-принтер.

На рисунке 3 представлена предлагаемая система сбора экологической информации о состоянии территориальной техносферы которая содержит: контрольные пункты промышленных стоков предприятий 1 , проводные каналы связи 2, локальные диспетчерские пункты контроля промышленных предприятий 3, радиоканалы связи 4, центральный диспетчерский пункт 5, первую группу датчиков экологического контроля состояния среды 6, вторую группа датчиков экологического контроля состояния среды 7, средства радиосвязи 8 с аппаратурой городской телефонной сети, аппаратура городской (региональной) телефонной сети 9, мобильные группы сбора информации 10.

Система работает следующим образом. Датчики 6 первой группы (для дистанционного) и второй группы (непосредственного мониторинга) измеряют концентрацию 3В, пространственные, временные и вероятностные параметры зон загрязнения, характеристики 
источников загрязнения и формируют типовое сообщение. Параллельно, для мониторинга водной среды контрольные пункты промышленных стоков предприятий 1 получают информацию о текущих значениях контролируемых параметров и передают показания в локальный диспетчерский пункт 3 контроля промстоков предприятия по кабельной 2-х проводной линии связи 2. Локальные диспетчерские пункты 3 концентрируют информацию о загрязнении водной среды и передают ее в центральный диспетчерский пункт 5 по радиоканалам связи 4.

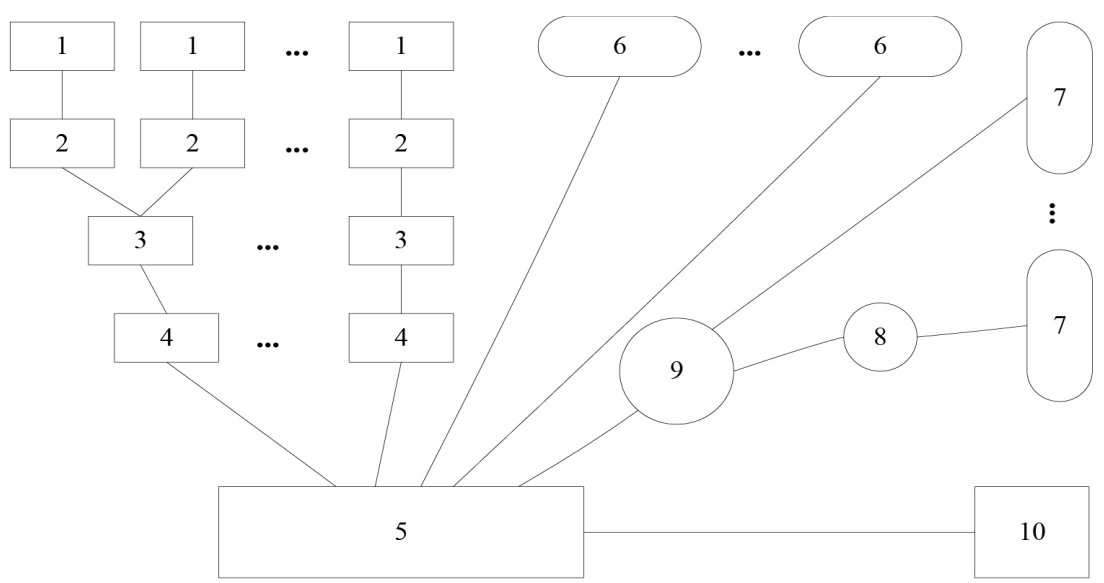

Рис. 3. Общая схема сбора и передачи информации о результатах мониторинга

Типовое сообщение датчиков 7 непосредственного и датчиков 6 дистанционного экологического мониторинга передается по проводным (кабельным) линиям связи на центральный диспетчерский пункт 5 (при размещении этих датчиков 6, 7 в месте дислокации центрального диспетчерского пункта 5). При перемещении (в сторону удаления) места расположения датчиков 6, 7 от центрального диспетчерского пункта 5, благодаря использованию абонентского пункта аппаратуры городской (региональной) телефонной сети 9, можно передать типовое сообщение. Сообщение передается с использованием модема по городской телефонной сети 9 на центральный диспетчерский пункт 5. 
При мониторинге мест, удаленных от городской (региональной) телефонной сети 9, с помощью датчиков 7 непосредственного мониторинга, передача типового сообщения осуществляется по средствам радиосвязи 8. Причем, передатчик средства радиосвязи 8 соединен с датчиком 7 непосредственно мониторинга, а приемник с абонентским пунктом аппаратуры городской телефонной сети 9 (на чертеже не показан).

При установлении факта превышения предельно допустимых значений измеренных датчиками первой или второй групп для уточнения ситуации в указанную зону отправляют БЛА, оборудованный приборами контроля (датчики третьей группы). БЛА имеет возможность безопасно для персонала находиться в зоне с повышенными значениями поражающих факторов, передавая информацию в режиме реального времени.

Центральный диспетчерский пункт 5 собирает информацию об экологическом состоянии города (региона), регистрирует ее и представляет с помощью технических средств как в автоматическом, так и в диалоговом режимах, а также передает информацию об экологическом состоянии территориальной техносферы в вышестоящие и смежные системы экологического мониторинга.

Очевидно, что предложенная система не ограничивается описанным примером осуществления. Для ее реализации могут быть предусмотрены и другие варианты, например в случае применения датчиков дистанционного мониторинга, в типовом сообщении которых отсутствует информация о дальности до источника загрязнения, на центральном диспетчерском пункте необходимо решение корреляционно базовых задач.

Предлагаемая система комплексного мониторинга может служить прототипом обсуждаемого в настоящее время проекта правил создания и эксплуатации систем автоматического контроля выбросов загрязняющих веществ, сбросов загрязняющих веществ. В этом документе предлагается создание подобных систем мониторинга, в составе предприятий являющихся наиболее значимыми загрязнителями окружающей среды. 
Таким образом, можно сделать вывод, о том, что предлагаемая нами система трехступенчатого мониторинга территорий является универсальной и применимой как для сельскохозяйственных территорий, так и для городских территорий с развитой промышленностью, меняется только система передачи информации, а в случае сельхозпредприятий делается особый «упор» на постоянный мониторинг почв. Сейчас это становится очень актуальным, так как проведение постоянного мониторинга ведет к возможности осуществления комплексных улучшающих мероприятий по использованию земельных и водных ресурсов, обеспечивающих получение наивысшей экономической отдачи от земельных угодий, с одной стороны, и сохранение их продуктивности и воспроизводства почвенного плодородия, с другой, является одним из ключевых направлений формирования и развития рационального природопользования на агромелиоративной основе $[13,14]$ Не следует забывать, что экологически ориентированные системы земледелия, такие как адаптивно-ландшафтные, базируются на формировании мелиоративных агроландшафтов как территориальной основе ведения сельского хозяйства и полномасштабном учете экологических закономерностей взаимодействия локальных экосистем в рамках относительно территориально обособленной местности с характерными именно для неё природными и антропогенными факторами [15, с. 39]. Поэтому система мониторинга является чрезвычайно важной именно для этих хозяйствующих субъектов.

\section{Заключение}

Предлагаемая схема сбора экологической информации с использованием специальным образом расположенных групп стационарных датчиков и датчиков, размещенных на БЛА, позволит своевременно получать достоверную информацию и оперативно реагировать на изменение состава воздушной и водной сред, почвы. Своевременное установление факта превышения предельно допустимых значений измеренных датчиками, сможет предотвратить развитие чрезвычайной ситуации и сохранить жизнь и здоровье населения, а для хозяй- 
ствующих объектов позволит осуществить переход на экономически обоснованный путь рационального природопользования.

\section{Список литературы}

1. Фомина А.О., Васильева Д.Д., Брумштейн Ю.М. Дистанционный мониторинг параметров окружающей среды: некоторые вопросы получения, передачи и использования данных // Астраханский вестник экологического образования. 2014. № 1 (27). С. 120-125.

2. Molev M.D., Stradanchenko S.G., Maslennikov S.A. Theoretical and experimental substantiation of construction regional security monitoring systems technospheric // ARPN Journal of Engineering and Applied Sciences, vol. 10, № 16, september 2015.

3. Penkova T.G., Korobko A.V., Nicheporchuk V.V., Nozhenkova L.F. Online modelling and assessment of the state of technosphere and environment objects based on monitoring data // Procedia Computer Science, №35 (2014), pp. 156-165, doi: 10.1016/j.procs.2014.08.095

4. Казаков В.А., Виноградов О.С., Виноградова, Н.А. Комплексный подход к автоматизации электрохимического производства // Экономика и управление. 2015. №1 (111). С. 60-66.

5. Основы государственной политики в области экологического развития Российской Федерации на период до 2030 года (утв. Президентом РФ 30.04.2012).

6. Иода Ю.В. Необходимость государственного воздействия на процессы согласования в системе экономических интересов // Социальноэкономические явления и процессы. 2011. № 3-4 (25-26). С. 118-124.

7. Маркин Л.С. Методика прогнозирования устойчивого развития социальной сферы сельских территорий / Л.С. Маркин, Е.Д. Маркина // Проблемы развития АПК региона (Махачкала). 2015. Т. 23, № 3 (23). C. $115-119$.

8. Данилина Н.Ю. Социально-эколого-экономическая эффективность организации использования мелиорированных земель / Н.Ю. Данилина, Е.Л. Уварова // Роль молодых ученых в решении актуальных задач АПК: сб. научн. труд. междунар. научно-практич. конф. молодых учёных. Санкт-Петербург. 2017. С. 196-200. 
9. Краснощеков В.Н. Теория и практика эколого-экономического обоснования комплексных мелиораций в системе адаптивно-ландшафтного земледелия : монография. Москва: МГУП, 2001. 293 с.

10. Способ формирования сети постов экологического мониторинга воздушной среды города: пат. 2597671 РФ: МПК G01W 1/00. / Крупина Н.Н., Киприянова Е.Н.; патентообладатель и заявитель «СанктПетербургский государственный университет аэрокосмического приборостроения» (ГУАП), № 2015110798/28; заявл. 25.03.2015; опубл. 20.09.2016 Бюл. № 26.

11. Способ комплексного мониторинга окружающей среды: пат. 2014153315 РФ: МПК G01W 1/00 (2006.01) / Босиков И.И., Цгоев Т.Ф.; патентообладатель и заявитель ФГБОУПО Северо-осетинский государственный университет им. К.Л. Хетагурова, № 2014153315; заявл 25.12.2014; опубл. 20.07.2016, Бюл. № 20.

12. Федеральный закон «Об охране окружающей среды» от 10.01.2002 № 7-Ф3.

13. Поляков В.В. Инструментарно-структурный механизм решения проблем землепользования в новых условиях хозяйствования / В.В. Поляков, Н.Б. Сухомлинова // Экономика и экология территориальных образований. 2018. Т.2, № 1(14). С. 22-33.

14. Комов Н.В. Комплексный подход к планированию и рациональному использованию земельных ресурсов / Н.В. Комов, А.С. Чешев // Экономика и экология территориальных образований. 2018. Т. 2 , № 1(14). С. 6-21.

15. Вольнов В.В. Комплекс мелиоративных мероприятий в адаптивноландшафтном земледелии / В.В. Вольнов, А.В. Бойко // Вестник Алтайского государственного аграрного университета. 2015. № 4 (126). С. 35-40.

\section{References}

1. Fomina A.O., Vasilyeva D.D., Brummshtein Yu.M. Remote monitoring of environmental parameters: some issues of receiving, transmitting and using data. Astrakhan Journal of Environmental Education. 2014. № 1 (27), pp. 120-125. 
2. Molev M.D., Stradanchenko S.G. and Maslennikov S.A. Theoretical and experimental substantiation of construction regional security monitoring systems technospheric, ARPN Journal of Engineering and Applied Sciences vol. 10, № 16, september 2015.

3. Penkova T.G., Korobko A.V., Nicheporchuk V.V., Nozhenkova L.F. Online modelling and assessment of the state of technosphere and environment objects based on monitoring data. Procedia Computer Science №35 (2014), pp. 156-165, doi: 10.1016/j.procs.2014.08.095

4. Kazakov V.A., Vinogradov O.S., Vinogradova N. A. Integrated approach to electrochemical production automation. Ekonomika i upravlenie [Economics and management]. 2015. №1 (111), pp. 60-66.

5. Fundamentals of state policy in the field of environmental development of the Russian Federation for the period up to 2030 (approved. Russian President 30.04.2012).

6. Ioda Y.V. Neobkhodimost gosudarstvennogo vozdeistviya na protsessi soglosovaniya $\mathrm{v}$ sisteme ekonomicheskikh interesov. [The necessity of state influence on the negotiation process in the system of economic interests.] Sotsial 'no-ekonomicheskie yavleniya i protsessy [Socio-economic phenomena and processes], 2010, V.3, no 51, pp. 26-33 (in Russian).

7. Markin L.S., Markina E.D. Metodika prognozirovaniya ustoichivogo razvitiya sotsialnoi sferi selskihk territorii. [Method of forecasting the sustainable development of the social sphere of rural areas.] Problemy razvitiya APK regiona (Makhachkala) [AIC development problems of the region (Makhachkala)], 2015, V.23, no 3(23), pp. 115-119.

8. Danilina N.Y., Uvarova E.L. Sotsialno-ekologo-ekonomicheskaya effektivnost organizatsii ispolzovaniya meliorativnikh zemel [Social, ecological and economic efficiency of the organization reclaimed land use]. Rol'molodykh uchenykh $v$ reshenii aktual'nykh zadach APK: sb. nauchn. trud. mezhdunar. nauchno-praktich. konf. molodykh uchenykh [The role of young scientists in solving the urgent problems of AIC: collection of scientific papers of the international scientific-practical conference of young scientists], Saint Petersburg, 2017, pp. 196-200

9. Krasnoschekov V.N. Teoriya I praktika ekologo-ekonomicheskogo obosnovaniya kompleksnikh melioratsii v sisteme adaptivno-landshaftnogo 
zemledeliya [Theory and practice of ecological and economic assessment of complex land improvements in the system of adaptive-landscape agriculture]: monograph. Moscow, MSUP, 2001, pp. 293.

10. Krupina N.N., Kiprianova E.N. Sposob formirovaniya seti postov ekologicheskogo monitoringa vozdushnoy sredy goroda: pat. 2597671 $R F$ : MPK G01W 1/00 [The method of formation of a network of posts of ecological monitoring of air environment of the city: Pat. 2597671 Grew. Federation: IPC G01W 1/00]; the applicant and patentee "Saint-Petersburg state University of aerospace instrumentation" (SUAI), No. 2015110798/28; Appl. 25.03.2015; publ. 20.09.2016 bull. No. 26.

11. Bosikov I.I., Tsgoev T.F. Sposob kompleksnogo monitoringa okruzhayushchey sredy: pat. 2014153315 RF: MPK G01W 1/00 (2006.01) [Method of integrated environmental monitoring: Pat. 2014153315 Grew. Federation: IPC G01W 1/00 (2006.01)]. / patentee and applicant of the North Ossetian state University. K.L. Hetagurova, № 2014153315; zayavl25.12.2014; publ. 20.07.2016, Byul. No. 20.

12. Federal'nyy zakon «Ob okhrane okruzhayushchey sredy» ot 10.01.2002 № 7-FZ [Federal law” On environmental protection “ of 10.01.2002 № 7-FZ].

13. Polyakov V.V., Sukhomlinova N.B. Instrumentarno-strukturnii mekanizm resheniya problem zemlepolzovaniya $\mathrm{v}$ novikh usloviyakh khozaystvovaniya [Instrumental-structured mechanism for resolving land use issues in new economic conditions]. Ekonomika i ekologiya territorial'nykh obrazovaniy [Economy and ecology of territorial formations], 2018, V.2, no 1(14), pp. 22-33 (in Russian).

14. Komov N.V., Cheshev A.S. Kompleksnii podkhod k planirovaniu I ratsialnomu ispolzovaniu zemelnikh resursov [An integrated approach to the planning and management of land resources]. Ekonomika i ekologiya territorial'nykh obrazovaniy [Economy and ecology of territorial formations], 2018, V.2, no 1(14), pp. 6-21.

15. Volnov V.V., Boyko A.V. Kompleks meliorativnikh meropriyatiy v adaptivno-landshaftnom zemledelii [Complex of ameliorative measures in the adaptive-landscape agriculture]. Vestnik Altayskogo gosudarstvennogo agrarnogo universiteta, 2015, no 4(126), pp. 35-40. 


\section{ДАННЫЕ ОБ АВТОРАХ}

Виноградов Олег Станиславович, доцент кафедры «Защита в чрезвычайных ситуациях», кандидат технических наук ФГБОУ ВО «Московский государственныий университет технологий и управления им. К.Г. Разумовского (Первый казачий университет)»

ул. Володарского 6, г. Пенза, Пензенская область, 440005, Российская Федерация fox-bbs@mail.ru

Виноградова Наталья Александровна, доцент кафедры «Защита в чрезвычайных ситуациях», кандидат технических наук ФГБОУ ВО «Московский государственньий университет технологий и управления им. К.Г. Разумовского (Первый казачий университет)»

ул. Володарского 6, г. Пенза, Пензенская область, 440005, Российская Федерачиия

woinova53@mail.ru

Безбородова Оксана Евгеньевна, магистр кафедры «Защита в чрезвычайных ситуациях», кандидат технических наук ФГБОУ ВО «Московский государственный университет технологий и управления им. К. Г. Разумовского (Первый казачий университет)»

ул. Володарского 6, г. Пенза, Пензенская область, 440005, Российская Федеращия

oxana243@yandex.ru

\section{Шерстнев Владислав Вадимович, аспирант}

ФГБОУ ВО «Московский государственный университет технологий и управления им. К.Г. Разумовского (Первый казачий университет)»

ул. Володарского 6, г. Пенза, Пензенская область, 440005, Российская Федерация

oxana243@yandex.ru 


\section{DATA ABOUT THE AUTHORS}

Vinogradov Oleg Stanislavovich, Associate Professor of "Protection in Emergency Situations", Candidate of Technical Sciences

K.G. Razumovsky Moscow State University of technologies and management (the First Cossack University)

6, Volodarsky str., Penza, Penza region, 440005, Russian Federation

fox-bbs@mail.ru

SPIN-code: 7817-1214

Vinogradova Natalia Aleksandrovna, Associate Professor of "Protection in Emergency Situations", Candidate of Technical Sciences K.G. Razumovsky Moscow State University of technologies and management (the First Cossack University)

6, Volodarsky str., Penza, Penza region, 440005, Russian Federation

woinova53@mail.ru

SPIN-code: 5470-0308

Bezborodova Oksana Evgenievna, Master of the Department "Protection in Emergency Situations", Candidate of Technical Sciences K.G. Razumovsky Moscow State University of technologies and management (the First Cossack University)

6, Volodarsky str., Penza, Penza region, 440005, Russian Federation

oxana243@yandex.ru

SPIN-code: 3519-3682

Sherstnev Vladislav Vadimovich, postgraduate

K.G. Razumovsky Moscow State University of technologies and management (the First Cossack University)

6, Volodarsky str., Penza, Penza region, 440005, Russian Federation

oxana243@yandex.ru 